\title{
The Promotion of Equality and Prevention of Unfair Discrimination Act 4 of 2000: Proposals for Legislative Reform to Promote Equality through Schools and the Education System
}

\author{
Anton Kok, Lwando Xaso, Annalize Steenekamp \& Michelle Oelofse*
}

\section{Abstract}

In this article, we focus on how the education system can be used to promote equality in the context of changing people's hearts and minds - values, morals and mindsets. The duties contained in the Promotion of Equality and Prevention of Unfair Discrimination Act 4 of 2000 ('Equality Act') bind private and public schools, educators, learners, governing bodies and the state. The Equality Act calls on the state and all persons to promote substantive equality, but the relevant sections in the Equality Act have not been given effect yet, and are therefore currently not enforceable. We set out how the duty to promote equality should be concretised in the Equality Act to inter alia use the education system to promote equality in schools; in other words, how should an enforceable duty to promote equality in schools be fashioned in terms of the Equality Act. Should the relevant sections relating to the promotion of equality come into effect in their current form, enforcement of the promotion of equality will take the form of obliging schools to draft action plans and submit these to the South African Human Rights Commission. We deem this approach inadequate and therefore propose certain amendments to the Equality Act to allow for a more sensible monitoring of schools' duty to promote equality. We explain how the duty to promote equality should then play out practically in the classroom to facilitate a change in learners' hearts and minds.

Keywords: Transformative pedagogy, equality legislation, promotion of equality, law reform, using law to change hearts and minds
Anton Kok is Professor of Jurisprudence at the Faculty of Law of the University of Pretoria. Lwando Xaso is an independent lawyer, writer and historian. Annalize Steenekamp, LLM, is a Multidisciplinary Human Rights graduate from the University of Pretoria. Michelle Oelofse is an Academic associate and LLM candidate at the University of Pretoria. Our thanks to Ms Nikita Meyer for her research assistance and other inputs in finalising this article. Our thanks to Ms Nikita Meyer for her research assistance and other inputs in finalising this article.

\section{Introduction}

The Promotion of Equality and Prevention of Unfair Discrimination Act ${ }^{1}$ is an omnibus law concretising Section 9(4) of the South African Constitution. ${ }^{2}$ The Equality Act binds the state and all persons, ${ }^{3}$ and prohibits hate speech, ${ }^{4}$ harassment ${ }^{5}$ and unfair discrimination. ${ }^{6}$ The Equality Act prohibits these causes of action in all spheres of South African life, and (at least in theory) reaches into the most intimate and private spaces as well. ${ }^{7}$ The Equality Act also clearly aims at facilitating attitudinal change (transformation of hearts and minds) $;^{8}$ to some extent via the equality courts, but mainly through the parts of the Act that deals with the promotion of equality. However, the sections in the Act pertaining to the promotion of equality have not come into force yet. Draft regulations on the promotion of equality have been published more than 15 years ago but have not been operationalised. ${ }^{9}$

Several racial incidents in South African schools have recently been exposed by outspoken learners. In 2016, Pretoria Girls High School faced a backlash after its learners revealed how the school's code of conduct unfairly discriminated against black students. ${ }^{10}$ In 2017 ,

1. Act 4 of 2000; hereafter 'the Act' or 'the Equality Act'.

2. The Constitution of the Republic of South Africa, 1996 (hereafter 'the Constitution'). Section 9(4) of the Constitution provides: 'No person may unfairly discriminate directly or indirectly against anyone on one or more grounds in terms of Subsection (3). National legislation must be enacted to prevent or prohibit unfair discrimination'. The national legislation referred to here is the Equality Act.

3. Section 5 of the Equality Act.

4. Section 10 of the Equality Act.

Section 11 of the Equality Act.

Section 6 of the Equality Act.

. J.A. Kok, A Socio-Legal Analysis of the Promotion of Equality and Prevention of Unfair Discrimination Act 4 of 2000. LLD Thesis University of Pretoria (2008), 145-6. Also see Section 7(d) and 7(i) that clearly strike at intimate, private spaces.

8. Kok (2008), above n. 7, at 9-11.

9. GN No 563, Government Gazette No 26316, 2004-04-30.

10. K. Ngoepe, Black Girls in Tears at Pretoria School Hair Protest, News24, 29 August 2016 www.news24.com/SouthAfrica/News/black-girls-intears-at-pretoria-school-hair-protest-20160829 (last visited 10 January 2018). The High Court has also ruled that the exclusion of a learner 
St Johns College in Johannesburg eventually dismissed a teacher who had initially been allowed to continue teaching at the school despite being found to have victimised pupils based on their race. ${ }^{11}$ An inclusive education is an education that does not unfairly discriminate, welcomes learners from diverse backgrounds and caters to their diverse needs.

The prohibition of unfair discrimination, as in the above scenarios, is a negative right, as it only requires an abstinence from conduct that amounts to unfair discrimination, versus actively putting in place measures to ensure a more equal society. Henrard writes about the European Court of Human Rights (ECtHR)'s engagement with cases brought on the basis of its prohibition of discrimination rules. ${ }^{12}$ In an analysis of ECtHR cases relating to discrimination, it was found that the court moved towards analysing discrimination on the basis of protection provided (by the relevant institution) against discrimination - the 'degree of suspectness of the ground of differentiation' determines the level of scrutiny employed by the court upon investigating if the protection against such discrimination was/is sufficient. ${ }^{13}$ We argue that the promotion of equality as a positive act goes beyond the abstaining of discrimination (a negative right) and should lead to a reduction in occurrences of (discrete, insular cases of) discrimination.

In this article, we argue that the Equality Act forms part of South Africa's education law. The Equality Act provides an overarching value system which gives effect to the Constitution of the Republic of South Africa, 1996 (hereafter 'the Constitution') that should govern all decisions, conduct, policies and laws. It should also, at its most ambitious and idealistic, in line with the proactive nature of the Constitution, champion lasting changes in educators' and learners' attitudes and belief systems towards equality and, ultimately, the celebration of diversity. ${ }^{14}$ The Equality Act is a law of general application, applying to all spheres of life and all sectors of society, not just in the educational sphere. It is an overarching piece of legislation, second in importance to only the Constitution, and trumps all other South African legislation. ${ }^{15}$ The Equality Act is therefore drafted in general terms, to be applied in all sectors by considering the specific particularities and context of each

from class by the Leseding Technical School in Welkom, because of dreadlocks, worn for religious reasons, were inconsistent with the learner's basic right to education and right to not be discriminated against based on religion, see Radebe and Others v. Principal of Leseding Technical School and Others (1821/2013) [2013] ZAFSHC 111 (30 May 2013).

11. Timeslive, St John's College Fired for Racist Comments, 28 July 2017, www.timeslive.co.za/news/south-africa/2017-07-28-st-johns-collegeteacher-fired-over-racism/ (last visited 10 January 2018).

12. K. Henrard, 'The European Court of Human Rights, Ethnic and Religious Minorities and the Two Dimensions of the Right to Equal Treatment: Jurisprudence at Different Speeds?', 34 Nordic Journal of Human Rights 157 (2016).

13. Ibid., at 160

14. Compare MEC for Education: Kwazulu-Natal and Others v. Pillay 2008 (1) SA 474 (CC) paras. 65, 76, 92.

15. Section 5 of the Equality Act. issue. ${ }^{16}$ The proposed amendments to the Equality Act set out in more detail later in the article are therefore general amendments, not amendments specific to the educational sector. We do, however, point out the practical implications of these proposed amendments for the educational sector, specifically in the context of amendments being proposed to facilitate changes in the hearts and minds of the South African population.

In earlier research, Kok pointed out that sociolegal scholars differ on the law's ability to steer attitudes and beliefs. ${ }^{17}$ Of the few authors who are of the view that law can influence attitudes, most offer stringent caveats. ${ }^{18}$ Pound and Cotterrell, amongst many others, hold the view that the lawmaker can aim to steer observable behaviour but not attitudes and beliefs. ${ }^{19} \mathrm{We}$ argue that South Africa offers a distinct case study as its Constitution implicitly mandates the legislature to proactively and positively put measures in place to facilitate the influencing of the hearts and minds of South African inhabitants - values, morals and mindsets.

The South African National Development Plan Vision 2030 relates social change via law to the Constitution which creates a values framework of 'collective convictions, joint and minimum ideological and normative choices of what a good society should be' and notes of the Constitution that it is a national compact that defines South Africa's common values and identifies our

16. E.g. cf. Section 14(2)(a) of the Equality Act.

17. J.A. Kok, 'Is Law Able to Transform Society?', 127 South African Law Journal 59-83 (2010).

18. M. Berger, Equality by Statute: Legal Controls over Group Discrimination. Columbia University Press: New York (1952) 172; R.L. Kidder, Connecting Law and Society: An Introduction to Research and Theory. Prentice-Hall: Englewood Cliffs (1983), 118-19 and 124; E. Chemerinsky, 'Can Courts Make a Difference?', in N. Devins and D.M. Douglas (eds.), Redefining Equality, Oxford University Press, Oxford (1998), 191-204, at 195; A. Sen, 'Normative Evaluation and Legal Analogues', in J.N. Drobak (ed.), Norms and the Law, Cambridge University Press, Cambridge (2006), 247-66, at 254; Kollapen in Sunday Times (2005-4-3) 18.

19. R. Pound, 'The Limits of Effective Legal Action', 3 The American Bar Association Journal 55-70, at 55 (1917); R. Cotterrell, The Sociology of Law: An Introduction. Butterworths: London (1992), 51-2; Wilson as discussed by Handler (1978), at 39; A. Allott, The Limits of the Law. Butterworths: London (1980), 231-2, at 40; L.M. Friedman, The Legal System: A Social Science Perspective. Russel Sage Foundation: New York (1975), 111-24; J.F. Handler, Social Movements and the Legal System: A Theory of Law Reform and Social Change. Academic Press Inc: New York (1978), 218; G.N. Rosenberg, 'The Irrelevant Court: The Supreme Court's Inability to Influence Popular Beliefs about Equality (or Anything Else)', in N. Devins and D.M. Douglas (eds.), (1998), 172-90, at 173 . To these authors may be added those who argue that any new law should not run too far ahead of society's current mores: A. Macfarlane, 'What Makes Effective Laws?', in H. Swain (ed.), Big Questions in History, Vintage London (2006), 101-7, at 105; J. Morison, 'How to Change Things with Rules', in S. Livingstone and J. Morison (eds.), Law, Society and Change, Dartmouth Aldershot (1990), 5-32, at 9; W.M. Evan, 'Law as an Instrument of Social Change', in W.M. Evan (ed.), The Sociology of Law: A Social-structural Perspective, Macmillan New York (1980), 554-62, at 557-60; W. Jeffrey Jr. 'Sociologists' Conceptualisations of Law: A Modest Proposal for Paradigm Revision', in P.J. Brantingham and J.M. Kress (eds.), Structure, Law, and Power: Essays in the Sociology of Law, Sage Beverly Hills (1979), 27-40, 38; Lundstedt as translated and interpreted by V. Aubert, In Search of Law: Sociological Approaches to Law. Martin Robinson: Oxford (1983), 13. Also see the contribution by Bocker in this special edition. 
rights and responsibilities as people living together' ${ }^{20}$ The Constitution is also the vision for South Africa and offers a blueprint for the establishment of a prosperous, non-sexist, non-racial and democratic society. ${ }^{21}$

The founding provisions of the Constitution state that South Africa is founded on the values of human dignity and equality as well as human rights and freedoms, ${ }^{22}$ non-racialism and non-sexism. ${ }^{23}$

The protection and advancement of these rights and values, in principle, have the power to change society because it protects freedom, dignity, equality, life and a whole host of other human rights and should ensure that no law or practice in society goes against these values. This transformative capacity of the Constitution is the essence of transformative constitutionalism.

Transformative constitutionalism has been defined as 'a long term project of constitutional enactment, interpretation and enforcement committed to transforming a country's political and social institutions and power relationships in a democratic participatory and egalitarian direction'. ${ }^{24}$ Former deputy chief justice Dikgang Moseneke noted that South Africa's constitutionalism is 'value-drenched'. ${ }^{25}$ If this is so, because of its status as the supreme law, all social institutions, power relationships, law and conduct then logically have to fit into the normative scheme created by the Constitution.

If it is true that various Constitutional Court judgements have been handed down where the values of compassion and tolerance have been emphasised, ${ }^{26}$ why is it that these values have not found their way into the hearts of South Africans and what is to be done? Sociolegal scholars offer a few ways in which attitudes may be steered: dramatic events such as a war or a depression, extraordinary leadership or the repeated circulation of ideas in the media, ${ }^{27}$ intricate and detailed knowledge of values-enforcing court decisions; ${ }^{28}$ and utilising the primary and secondary school system as a 'nationally inclu-

20. National Development Plan Vision 2030, 458.

21. Ibid.

22. Section 1 (a) of the Constitution of the Republic of South Africa Act 108 of 1996

23. Section $1(b)$

24. K. Klare, 'Legal Culture and Transformative Constitutionalism', 14 South African Journal of Human Rights 150 (1998)

25. D. Moseneke, 'A Journey from the Heart of Apartheid Darkness towards a Just Society: Salient Features of the Budding Constitutionalism and Jurisprudence of South Africa', Thirty-Second Annual Philip A. Hart Memorial Lecture. Georgetown University Law Center (2012), 22.

26. Prince v. President of the Law Society of the Cape of Good Hope 2002 (1) SACR 431 (CC) paras. 57, 79, 147; S v. Lawrence; S v. Negal; S v. Solberg 1997 (2) SACR 540 (CC) para. 147; S v. Makwanyane 1995 (2) SACR 1 (CC) paras. 249, 308, 369, 391; Hoffmann v. South African Airways 2001 (1) SA 1 (CC) para. 38; Pretoria City Council v. Walker 1998 (2) SA 363 (CC) para. 102.

27. Wilson, as discussed by Handler (1978), at 39. Handler (1978), at 220, puts it somewhat differently: 'Wilson... argue[s] that social change only really comes about by dramatic events, political entrepreneurs, or the gradual change of public opinion'. From this perspective, one could, e.g. argue that it was not the enactment of the interim Constitution that led to greater tolerance between the polarised racial groups in South Africa, but symbolic reconciliatory moments such as President Mandela's appearance in a Springbok jersey at the 1995 Rugby World Cup.

28. Rosenberg, above n. 19, at 174. sive socialising agent' ${ }^{29}$ In this article, we consider the last-mentioned proposal - the extent to which the school system can assist in concretising one of the Equality Act's aims to bring about changes in the hearts and minds of South Africans. ${ }^{30} \mathrm{We}$ argue below for the amendment of the Equality Act to achieve this goal (see the Annexure to the article for the detailed proposal).

We deal with the proposal in five parts. In the first part, we investigate the South African government's legislative mandate to not only enforce but also to promote a certain moral stance - that of substantive equality - in its citizens' lives. We then consider why schools should be utilised as one of the main instruments in facilitating changes in hearts and minds. Thirdly, we describe the current structure of the chapter in the Equality Act that deals with the promotion of equality, and how it may apply to schools. In the fourth part, we offer some lessons from the United Kingdom's approach in promoting equality, also as it may apply to the school system. In the last part, we propose an alternative, more workable method of promoting equality, in particular how these amendments may be applied to the basic education system, which considers current South African realities, in terms of which the value of substantive equality can be promoted and diversity celebrated using the Equality Act.

\section{The Legislature's Mandate to Influence Hearts and Minds}

Before the legislature can be urged, or the argument made that the legislature is responsible for implementing laws that will promote a specific moral stance, in this instance, substantive equality, one must consider why the legislature (should) have the power to interfere in private spheres of life.

For the sake of this South African-centred argument we argue that, core to the nature of the recent history of apartheid, legal development in South Africa has established a precedent that the legislature can, and ought to, interfere with moral affairs if the effect of not interfering would bring about unjustified inequality in the treatment of specific groups. We argue that South Africa's history and a transformative Constitution demand that the state positively interfere in inhabitants' lives based on constitutional values.

In a democracy, as originally intended, the power arguably vests in the people and they should determine the government's agenda and scope, not the other way around. If the legislature then enacts law seemingly in contradiction to the people's will, say law to promote moral change, such law would be undemocratic and,

29. A. Bestbier, 'Legal Literacy - the Key to a South African Supra-Culture', 15 Obiter 105-26, at 107-8 (1994)

30. See Kok (2008), above n. 7, at 7-9 
accordingly, it should not be of force. How to answer this argument? In the South African context, with a value-based Bill of Rights, transformation should be seen as the will of the people, in line with the said values, which provides the mandate for the South African democracy.

Late Chief Justice Langa (of the South African Constitutional Court) argues that the transformative nature of the Constitution is a continuous one, using the metaphor of a bridge, as described in the Epilogue of the interim Constitution:

[The Constitution is] a historic bridge between the past of a deeply divided society ... and a future founded on the recognition of human rights, democracy and peaceful co-existence and development opportunities for all South Africans, irrespective of colour, race, class, belief or sex. ${ }^{31}$

Langa chooses to interpret the bridge, representing transformation, not as a temporary phenomenon, where one crosses the bridge and the goal is reached, but rather as a continuous effort where 'the idea of change is constant' ${ }^{32}$

This bridge represents the traditional idea of a mandate. A mandate, in this instance, is given with a specific set of boundaries and instructions; the mandator being the people in a democratic society and the mandatee the state. It would seem that, using this idea of a mandate, people cannot provide a mandate for the state to change their morals; for changing the hearts and minds of the people, would not be a request that would come from the people. Rather, such a 'legitimate' mandate would be in line with the hearts and minds (the morals) of the people.

However, Langa's continuous bridge metaphor provides insight into the mandate provided by South Africans. Because of the 'permanent ideal'33 of transformation set in the values of the Constitution, the mandate dictates that change is the continuous goal, not a specific outcome. South Africans, through the Constitution, provides the mandate to the state, especially the legislature and the judiciary, of transformation - the continuous nature of such a mandate necessitates broadness, including the guidance of morality, even if that goes beyond the current moral stance. The purpose of such a broad mandate is transformation, with the only constant being the breaking from the apartheid past.

The Constitution, being the supreme law of South Africa, guides all legal matters in the country. ${ }^{34}$ The first test of the extent of the Constitution's reach was $S$ v.

31. Constitution of the Republic of South Africa, Act 200 of 1993 (own emphasis to highlight equality as Constitutional mandate). See P. Langa, 'Transformative Constitutionalism', 17 Stellenbosch Law Review 351 (2006).

32. Langa makes this argument in line with A. Van der Walt 'Dancing with Codes - Protecting, Developing and Deconstructing Property Rights in a Constitutional State', 118 South African Law Journal 258-96, at 296 (2001).

33. Langa, above n. 31, at 354 .

34. Section 2 of the Constitution.
Makmanyane, ${ }^{35}$ which ruled that the death penalty was inconsistent with the human rights contemplated in the interim Constitution. Capital punishment as sentence for crime is, in essence, a moral question, one often asked to be considered by the public. ${ }^{36}$

In Makmanyane, Justice Chaskalson dealt with public opinion being in conflict with judicial rulings, stating that:

The question before us ... is not what the majority of South Africans believe a proper sentence ... should be. It is whether the Constitution allows the sentence. $^{37}$

This ruling makes it clear that, if the Constitution necessitates change, the state is bound to guide the hearts and minds of South Africans through legal intervention. The continuous transformation mandate given by the people (as discussed above) is guided by constitutional values, rather than by public opinion.

In South Africa, same-sex marriage was legalised following the Constitutional Court ruling in Minister of Home Affairs v. Fourie ${ }^{38}$ on 1 December 2005. The Fourie ruling was based on the value of substantive equality, as contemplated in Section 9 of the Constitution. As mandated by the Constitutional Court, Parliament passed the Civil Union $\mathrm{Act}^{39}$ in 2006 to legalise same-sex unions, being only the fifth country in the word to do so at the time.

De Vos and Barnard point out that public support for the recognition of same-sex marriage leading up to the mentioned legislation to be in opposition to the Fourie ruling. ${ }^{40}$ Public hearings facilitated by Parliament related to the Civil Union Bill often led to 'homophobic rants', ${ }^{41}$ illustrating the public's reluctance to accept this moral determination made by the state. The contradiction in the public's opinion and the mandate, as found in the Constitution, is summarised by De Vos and Barnard, quite meaningfully, as follows:

It [the ruling party] had to comply with the court's judgment while aware that the vast majority of its voters were strongly opposed to it. ... It is one of the

35. 1995 (6) BCLR 665 (CC) (hereafter Makwanyane).

36. The question of allowing death penalty was considered by public vote in several United States of America states since 1916 (Arizona) until as recent as 2016 (California, Nebraska, Oklahoma), see: (https:// ballotpedia.org/Death_penalty_on_the_ballot). Citizens of the Republic of Ireland voted to van death penalty in 2001 (www.irishstatutebook.ie/eli/2001/ca/21/enacted/en/html).

37. Makwanyane, above n. 35 , para. 87

38. 2006 (1) SA 524 (CC) (hereafter Fourie).

39. 17 of 2006.

40. P. de Vos and J. Barnard, Same-Sex Marriage, Civil Unions and Domestic Partnerships in South Africa: Critical Reflections on an Ongoing Saga. 2015. https://constitutionallyspeaking.co.za/wp-content/ uploads/2015/11/Same-sex-marriage1.pdf.

41. Ibid., at 814, detailed in media reports: W.J. da Costa, 'Hearings "A Platform for Hate Speech"', Cape Times 11 October 2006, at 4; W.J. Costa, 'Gays Protest Tone of Civil Union Bill Debate', Cape Times 16 October 2006, at 4; W.J. da Costa, 'Activists Slam Hearings on SameSex Unions', Pretoria News 11 October 2006, at 4. 
implications of favouring the rule of law that it will not always accord with public opinion. ${ }^{42}$

De Vos further emphasised, discussing the Civil Union Act in 2007, that the Fourie victory was the result of '... luck, wise strategic leadership and fortitude', with a legal strategy relying on Section 9's sexual orientation inclusion and not societal approval of same-sex marriages. ${ }^{43}$

The action taken by the judiciary in Fourie and the subsequent compliance by Parliament indicate that the South African state interprets the constitutional values as its guiding principles when it is faced with a moral issue. The South African state has a clear mandate to guide the hearts and minds of South Africans through law.

\section{Why Focus on Schools in Promoting Equality?}

According to the theories of Yezekiel Dror, a lag in social change will exist if people understand the law but the norms introduced by the law differs from their existing norms, ${ }^{44}$ and 'when social behaviour and the sense of obligation generally felt towards legal norms significantly differs from the behaviour required by law'. ${ }^{45}$ This implies that the gap between constitutional literacy and internalisation will potentially cause a lag in social change.

Values and norms are acquired through processes of learning and socialisation. ${ }^{46}$ Socialisation is a process of internalising the norms and ideologies of society. ${ }^{47}$ Learning happens via agents of socialisation or influencers, which can be seen as individuals, groups and institutions that alter individual attitudes, behaviours and beliefs to conform. ${ }^{48}$

The three main traditional agents of socialisation are the family, the community ${ }^{49}$ and the school. ${ }^{50}$ As society changes, religious, communal and family values, and hence the education they provide, do not stay constant either. This makes family and community unstable socialising agents, and hence are not the ideal platforms. Schools, on the other hand, use one uniform national framework or curriculum to determine their values,

42. de Vos and Barnard, above n. 40, at 820

43. P. de Vos, 'The 'inevitability' of Same-Sex Marriage in South Africa's Post-Apartheid State', 23 South African Journal on Human Rights 432-65 (2007).

44. Y. Dror, 'Law and Social Change', 33 Tulane Law Review 787, at 790 (1959).

45. Ibid., at 794

46. J. Saldana, 'Power and Conformity in Today's Schools', 3 International Journal of Humanities and Social Science 228, at 228 (2013).

47. M. Hirsch, Invitation to the Sociology of International Law. Oxford University Press: Oxford (2015), at 7-8.

48. Saldana, above n. 46 , at 228.

49. S. Amon, S. Shamani \& Z. Ilatov, 'Socialization Agents and Activities of Young Adolescents', 43 Adolescence 373 (2008).

50. Saldana, above n. 46 , at 228. which makes it easy to see why Bestbier refers to schools as 'nationally inclusive socialising agents';' and Saldana considers them the most stable and formal agent of socialisation. ${ }^{52}$

The reason why schools are arguably the best option for socialisation lies in Greenfield's theory of 'transitional community'. Patricia Greenfield theorises that the learning and development pathway for children becomes complicated because of the family's and community's role as socialising agents, delivering different normative messages of individualism versus collectivism: ${ }^{53}$

Under these conditions, the theory of social change and human development predicts that children will be subject to cross-cutting currents, in that they will receive both socialisation messages at home that continue to be adapted to the more gemeinschaft environment that their parents grew up in and conflicting socialisation messages from representatives of the more gesellschaft host society, such as teachers.

Schools are hence an essential way to address the gap between the two prototypes and cause an intervention between gemeinschaft and gesellschaft and different normative frameworks because they essentially create what we could call 'transitional communities'.

So this means that if we want to socialise the transformative values (as contained in the normative structure of the Constitution) into society and bridge the gap between our differing normative structures to achieve real social change, we should focus on education as a socialising agent, specifically schools that create transitional communities.

If we hence want the constitutional values to actually change people's thinking, these constitutional values must be internalised. Mere knowledge or understanding or 'constitutional literacy' is not enough. How to achieve this internalisation?

Paulo Freire calls this step critical consciousness/conscientização, which involves dialogue, reflection and praxis/action. ${ }^{54}$ Freire considers that the main problem with education lies in 'narration sickness' 55 The relationship between a teacher and student is one of an active narrator and a passive listener: 'The contents, whether values or empirical dimensions of reality, tend in the process of being narrated to become lifeless and petrified' ${ }^{56}$ This leads to what he calls the 'banking concept' of education through which students are simply keeping deposits as passive recipients in the classroom and are 'receptacles

51. Bestbier, above n. 29, at 108

52. Saldana, above n. 46 , at 228

53. P.M. Greenfield, 'Linking Social Change and Developmental Change: Shifting Pathways of Human Development', 45 Developmental Psychology 401, at 411-2 (2009)

54. P. Freire, Education and Critical Consciousness. Bloomsbury Academic (2005), 43.

55. P. Freire, Pedagogy of the Oppressed. Continuum: New York (2005), 72.

56. Ibid., at 72 
to be filled by the teacher' ${ }^{57}$ The problem with this approach to education is that: ${ }^{58}$

The more students work at storing the deposits entrusted to them, the less they develop the critical consciousness which would result from their intervention in the world as transformers of that world. The more completely they accept the passive role imposed on them, the more they tend simply to adapt to the world as it is and to the fragmented view of reality deposited in them.

This approach arguably leads to students having a disconnect with their social realities because they are passive in those realities and do not feel an inclination towards having a responsibility to change those realities. On the other hand, using a more active educational method of critical enquiry through problem-posing education instead of banking education creates a space for dialogue where 'multiple voices are honored but not unquestioned; stories and perspectives are entered into the educational arena to serve as entries for critical social interrogation'. ${ }^{59}$ When problems are posed and dialogue is had about those problems, students do not simply receive knowledge or achieve literacy, they are forced to think critically about situations. According to Nagda et $a l$., 'in this democratic and emancipatory process, students and teachers engaged in dialogic pedagogy can become active citizens, challenging injustices both within and among themselves, and in the social world around them'. ${ }^{60}$

Dialogue and reflection about problems can potentially help create a critical consciousness: ${ }^{61}$

Critical consciousness, which encompasses being aware of power relations, analyzing habits of thinking, challenging discursive and ideological formations, and taking initiative, is developed in studentcentered dialogue that problematizes generative themes from everyday life, topical issues from society, and academic subject matter from specific disciplines.

In a dialogue and subsequent critical consciousness, students as well as teachers can contextualise their experiences socially, culturally and historically and subsequently also recognise the potential to change oppressive structures. ${ }^{62}$ According to Freire, dialogue and reflection are not sufficient. He argues for praxis as well, which entails that

\footnotetext{
57. Ibid., at 73

58. Ibid., at 73

59. B.A. Nagda, P. Gurin \& GE. Lopez, 'Transformative Pedagogy for Democracy and Social Justice', 6 Race Ethnicity and Education 165, at 168 (2003).

60. Ibid

61. J. Kaufmann, 'The Practice of Dialogue in Critical Pedagogy', 60 Adult Education Quarterly 455, at 458 (2010).

62. Ibid., at 458 .
}

it is not enough for people to come together in dialogue in order to gain knowledge of their social reality. They must act together upon their environment in order critically to reflect upon their reality and so transform it through further action and critical reflection. ${ }^{63}$

Through a critical consciousness about issues, dialogue and reflection, students can then take informed action (praxis) which is based on values. ${ }^{64}$ Hence for Freire, the essential elements of education have to be dialogue and reflection that create a critical consciousness from which action can be taken. In the context of this discussion, we can hence consider that following a literacy or an understanding of laws or values, learners thus have to subsequently actually become conscious of those values by reflecting on them via dialogue to be introspective about how it affects their social reality and then only will they be inspired to act on the basis of those values in society; otherwise, they are unconnected to their own society (similar to Bestbier's notion of legal impotence). ${ }^{65}$ How such a dialogue can be facilitated in (or even forced upon) schools using the Equality Act is addressed in the next sections.

\section{The Equality Act's Commandment to Promote Equality}

The Equality Act prohibits unfair discrimination, hate speech and harassment - conduct; or outward manifestations of implicit or explicit bias. ${ }^{66}$ The state and 'all persons' are prohibited from these actions. The definitions of 'State' and 'person' in the Act are broad enough to include educators, learners, governing bodies and all role players in the schooling system. Complaints which fall under the equality court's jurisdiction probably occur on a daily basis in classrooms and school grounds across South Africa. These instances may all be adjudicated on in equality courts.

However, in this article, we focus on the part of the Equality Act that deals with the promotion of equality the part that addresses changes in hearts and minds and not the adjudication of complaints by the equality courts. As stated earlier, the part of the Equality Act that deals with the promotion of equality is not in force yet.

Chapter 5 of the Equality Act, in its current form, presupposes that the model to be followed when concretising the duty to promote equality is that of prescribing

63. https://freire.org/paulo-freire/concepts-used-by-paulo-freire (last visited 29 July 2019).

64. http://infed.org/mobi/paulo-freire-dialogue-praxis-and-education/ (last visited 29 July 2019).

65. Bestbier, above n. 29, at 113 quoting Fitzgerald 'Law at school - a Canadian viewpoint' 1978 New Law Journal 300.

66. See Subsection 6 to 11 of the Act. 
equality plans and action plans and having these plans submitted to a monitoring body. To operationalise this chapter in the Equality Act, regulations would have to be effected to make provision for equality plans, action plans, the monitoring of these plans and some enforcement mechanism if plans are neither drafted nor implemented.

Draft regulations dealing with the promotion of equality in the general sense have been published for comment, ${ }^{67}$ but have not yet been given legal effect. The regulations distinguish between the promotion of equality by the state, and the promotion of equality by 'all persons'. As to the state's obligations, the regulations envisage the drafting of equality plans by state departments. ${ }^{68}$ These plans must be drafted for a five-year period. These plans must then be submitted to the South African Human Rights Commission (SAHRC), which in turn must submit the plan to the Commission for Gender Equality (CGE) for purposes of consultation. The SAHRC is a national institution created by Chapter of the Constitution. Section 184 of the Constitution sets out the mandate of the SAHRC which states that the SAHRC must promote respect for human rights and a culture of human rights; promote the protection, development and attainment of human rights; and monitor and assess the observance of human rights in the Republic. Therefore, the role assigned to the SAHRC by the draft regulations falls squarely within the mandate of the SAHRC. In terms of the draft regulations, the SAHRC must consider and assess each of these equality plans, make appropriate recommendations to the relevant state department and report to the National Assembly in terms of Section 181(5) of the Constitution. (Section 181(5) states that Chapter 9 institutions are accountable to the National Assembly.) In terms of the draft regulations, each state department must also submit annual progress reports to the SAHRC, which must then assess each of these progress reports and if, necessary, must advise the relevant departments on measures to be put in place to expedite the implementation of the equality plan. ${ }^{69}$

As to the promotion of equality by 'all persons', Section 28 of the draft regulations distinguishes between 'entities' that employ more than 150 employees, more than 50 but less than 150 employees and less than 50 employees. Entities that employ more than 150 employees must submit equality plans to the Director-General of the Department of Justice and Constitutional Development. These plans are valid for five years. Annual progress reports must also be submitted to the Department. The Director-General then forwards the plans to the appropriate national state department and that department then analyses the plans. The progress reports are dealt with on a similar basis. Entities that employ between 50 and 150 employees must adopt written measures to promote equality and must report in writing thereon upon

67. GN 563, above n. 9, at 26316

68. See Chapter VI, Section 24 of the draft regulations.

69. Section 26 of the draft regulations. the written request of a national state department. It must also, on request of a member of the public, cause its plan to be made available for inspection at its offices. Entities with less than 50 employees must adopt written measures to promote equality and must report in writing thereon upon the written request of a national state department.

The most obvious question relating to these draft regulations is whether the SAHRC and the various state departments will have the capacity to rigorously assess and monitor compliance with the equality plans and progress reports. ${ }^{70}$

The draft regulations pertaining to the promotion of equality cannot be successfully implemented without the heavy involvement of the SAHRC. The SAHRC will have to do the heavy lifting with the management of the equality plans envisioned by the Equality Act in its current form. The draft regulations task the SAHRC with a number of duties in respect of the equality plans such as assessing whether the measures to be implemented will achieve the stated goals and objectives and assessing whether the measures adopted to monitor the implementation of the equality plans are appropriate amongst others. ${ }^{71}$ This is bound to be a mammoth task for the SAHRC as it will have to draft guidelines and codes to guide the entities that have to submit equality plans on how to actually compile these plans. Then it will have to assess and monitor the compliance of these entities with the Equality Act and its regulations amongst other tasks.

In its Trends Analysis ${ }^{72}$ Report, the SAHRC states that alleged infringements of the right to equality comprised an overwhelming majority of the complaints received by the SAHRC. In the 2015/2016 financial year, the Commission received a total of 749 equality-related complaints. It received 428 complaints regarding alleged violations of socio-economic rights. This work load excludes the litigious work it does in the High Courts, Supreme Court and Constitutional Court and it excludes complaints in respect of the other rights violations falling outside of socio-economic rights. It also excludes the monitoring the SAHRC is mandated to do in terms of the Promotion of Access to Information. Suffice to say that the SAHRC already has a huge mandate which may affect its ability to take on the added monitoring responsibility in terms of the Act.

In this article, we proceed from the assumption that the SAHRC will not in the foreseeable future be empow-

70. Compare S. Jagwanth, 'Affirmative Action in a Transformative Context: The South African Experience', 36 Connecticut Law Review 725-46, at 744 (2003). More recently, the Auditor-General has lamented the high rate of non-compliance by national and provincial government with key legislation. See audit outcomes of national and provincial government departments available on https://www.gov.za/sites/default/files/ speech_docs/Audit\%20Outcomes\%202015-16\%20PFMA \%20Presentation.pdf. (last visited 5 October 2020).

71. See Section 25 of the draft regulations.

72. See the South African Human Rights Commission Annual Trends Analysis Report 2015/2016 Financial Year, available at www.sahrc.org.za/ home/21/files/Annual_Trends_Analysis_\%20Report_2015_16.pdf (last visited 17 October 2018). 
ered to be able to deal with millions of submitted equality plans. We therefore argue for an alternative approach to promote equality in terms of the Equality Act including how schools should be asked to promote equality.

\section{Lessons from the UK Experience in Promoting Equality in the School System}

The UK model for the advancement of equality requires public and private bodies to submit equality plans and concomitant action plans. The United Kingdom also provides a guideline which outlines how the UK Equality Act 2010 is to be promoted in schools in relation to the provision of education and access to benefits, facilities or services, both educational and noneducational. It provides an authoritative, comprehensive and technical guide on how schools can implement the requirements of the United Kingdom's Equality Act.

The guideline is also a useful guide on how to approach issues such students undergoing gender reassignment and bullying (based on prohibited grounds) in schools and to incorporate these issues into the curriculum. ${ }^{73}$

The guideline provides an example of how the promotion of equality can be pursued through the schooling system. For example, the guideline provides that schools must not

- discriminate against a pupil or prospective pupil because of their disability, race, sex, gender reassignment, religion or belief or sexual orientation;

- harass or victimise a pupil or prospective pupil.

Further, it provides that schools must not discriminate against a person in relation to the following activities

- admission to school;

- $\quad$ the provision of education to pupils;

- access to any benefit, facility or service;

- exclusion from school by subjecting a pupil to any other detriment.

A school must not

- discriminate in the way it provides education for a pupil;

- discriminate in the way it gives a pupil access to any benefit, facility or service;

- refuse to provide education for a pupil for discriminatory reasons;

- refuse to give a pupil access to a benefit, facility or service;

- harass a pupil;

73. E.g. www.equalityhumanrights.com/en/publication-download/ technical-guidance-schools-england www.equalityhumanrights.com/en/publication-download/tips-tacklingdiscriminatory-bullying (last visited 24 December 2017).
- victimise a pupil.

Schools must have in place either

- a three-year race equality policy and action plan; accessibility plan; disability equality scheme and action plan; gender equality scheme and action plan; equal opportunities policy that covers sexual orientation, age and religion and belief; and a strategy for promoting community cohesion; or

- a three-year single equality scheme and action plan that incorporates all the above policies, schemes and plans.

Schools need to be careful that blanket uniform policies do not discriminate because of race, religion or belief, gender, disability, gender reassignment or sexual orientation. Consequently, it will be up to the individual school to consider the implications their uniform requirements have on their pupils. ${ }^{74}$

Schools need to make sure that pupils of all races are not singled out for different and less favourable treatment from that given to other pupils. Schools should check that there are no practices which could result in unfair, less favourable treatment of such pupils. For example, it would be unlawful for a selective school to impose a higher standard for admission to applicants from an ethnic minority background

Similar to the South African draft regulations, the United Kingdom's model requires private bodies to submit their equality plans and concomitant action plans to the designated monitoring body and it is clear to these bodies that these plans will be scrutinised. As to who monitors compliance, the answer is twofold.

i. Public and private bodies will internally have to set up monitoring schemes which have to be approved by the monitoring body. Examples of internal monitoring include recording and producing data, surveys and spot check exercises. The methods should be clearly described and appropriate to what is being monitored. Public and private bodies should designate internal teams or an internal equality officer whose duty it will be to drive the process. Service users can also play a role in the monitoring process and could offer feedback.

ii. The other layer of monitoring will come from the external monitoring body. The United Kingdom's Equality Commission has issued a Compliance and Enforcement Policy setting out its powers and objectives in that regard. In that policy, the Commission states that it sees its role as regulatory helping organisations achieve what they should, not trying to catch them out if they fall short. Legal action is the Commission's last resort.

Another issue that should be considered is how civil society can play a role in this monitoring process. Civil

74. The Equality Act and Schools: Departmental Advice for School Leaders, School Staff, Governing Bodies and Local Authorities, available at: https://assets.publishing.service.gov.uk/government/uploads/system/ uploads/attachment_data/file/315587/Equality_Act_Advice_Final.pdf (last visited 17 October 2018). 
society could be empowered to ask for information from a particular public or private body or to ask for a copy of the equality plan or action plan, and for information on progress in achieving the targets set in the action plan.

Perhaps the single most important lesson from the United Kingdom is that public authorities have to weave policies of equality into the fabric of its decisions and public policies. That is what the promotion of equality comes down to - a political commitment to make equality central in every aspect of the state's work. Equality plans are a written commitment, assessable and enforceable. This process will require resources - a committed work force and sufficient funds - for it to be a success. Otherwise, the fear expressed by an academic from the United Kingdom - that this whole process could result in the 'mumbo-jumbo of clichéd policy statements and bureaucratic procedures' without bringing about significant social change is a real danger - the only way that it can be prevented is by ensuring that the compliance and enforcement mechanisms are utilised. ${ }^{75}$ Taking into consideration the UK model, we argue that the duty to promote equality may be concretised in schools as follows:

- Incorporating equality principles (and equality law) into primary and high school curricula;

- Promoting a holistic school ethos and values that challenge prejudice-based discriminatory language, attitudes and behaviour;

- Using materials and resources in schools that reflect the diversity of the school, population and local community in terms of race, gender, sexual identity and disability, avoiding stereotyping;

- Preparing learners for life in a diverse society and ensuring that there are activities across the curriculum that promote the spiritual, moral, social and cultural development of pupils;

- Providing opportunities for pupils to appreciate their own culture and celebrate the diversity of other cultures. ${ }^{76}$

We return to these five proposals below. In the two sections that follow and in the Annexure, we show how the Equality Act may be amended to make these proposals compulsory for all South African schools.

75. B. Hepple, Equality: The New Legal Framework. Hart Publishing: Portland (2011), 179

76. More generally, the Department of Justice should also develop an 'equality journal' - a publication consisting of judgements of the magistrates and High Courts; personal reflections by presiding officers of the equality court; guidance for the benefit of mainly presiding officers on how to interpret the Equality Act. It should also develop an equality court website with summaries of cases in plain language that the media should be referred to regularly for reporting purposes, discussions on radio and incorporation into the story lines of television series. Plain language versions of the Equality Act should be prepared in all eleven official languages (see the proposed amendment to the regulations in the last part of the article - 'Availability of Act in official languages'. In this article, we treat as self-evident the benefits of a plain language approach. A full argument on why the Equality Act should be drafted in plain language is beyond the scope of this article).

\section{An Alternative Approach to the Promotion of Equality}

In this part of the article, we argue for amendments to the Equality Act and the existing draft regulations in relation to the promotion of equality. The assumption we make here is that the designated enforcement body in terms of the draft regulations - the SAHRC - is simply not in a position to monitor compliance with the Act. The approach set out in the Annexure asks much from individual schools and civil society instead.

To reiterate, the Equality Act is a national law that applies to the entire South Africa, across all sectors and public and private spheres of life. The Act is drafted in general language, to be applied context specifically for each individual case that may appear before the equality courts. The draft regulations on the promotion of equality are likewise drafted in general language, to be adapted by the particular organisations asked to develop equality plans. The amendments proposed in the Annexure are also proposed in general terms, not only for the education sector. The general gist of this article is, however, directed at schools as a particularly apt sector of society for addressing the transformation of hearts and minds. In the sections that follow, general amendments to the Act and the draft regulations are suggested, whereafter these suggested amendments are applied in particular to the education sector.

The following sections in the Equality Act's current form require the promulgation of regulations relating to the promotion of equality:

Section 25(3)(c): ‘... [T] he constitutional institutions ... are also competent to request from the Department [of Justice], in the prescribed manner, regular reports regarding the number of cases and the nature and outcome thereof'.

Section 25(4)(b): 'All Ministers must within their available resources prepare and implement equality plans, in the prescribed manner, which must include a time frame for implementation and which must be formulated in consultation with the Minister of Finance'.

Section 25(5)(a): 'These equality plans must be submitted to the SAHRC to be dealt with in the prescribed manner'.

Section 26: 'Any person directly or indirectly contracting with the State or exercising public power must promote equality by making regular reports to the relevant monitoring authorities or institutions as may be provided in regulations'.

Section 27(2): 'The Minister of Justice must develop regulations to require companies, closed corporations, partnerships, clubs, sports organisations, corporate entities and associations, in a manner proportionate to their size, resources and influence, to 
prepare equality plans or abide by prescribed codes of practice or report to a body or institution to promote equality'.

The proposed amendments to the Equality Act and draft regulations set out in the Annexure to this article proceed from the assumption that the SAHRC and other possible monitoring agencies are not sufficiently staffed or resourced to undertake a comprehensive monitoring of submitted equality plans from every company, closed corporation, partnership, club, sport organisation, corporate entity and association, nor from every person directly or indirectly contracting with the state or exercising public power.

The changes we suggest to the Equality Act and draft regulations accompanying the Act would rather require these bodies to develop and then make their equality plans publicly available and accessible to the public. This may, e.g. be done by publishing the plans online and to have it available at the premises of the body to supply the plan when requested. Where a particular body fails to develop, or fails to make publicly available, or publishes an inadequate equality plan, it is proposed that the draft regulations should include a provision empowering the equality courts, on application by an appropriate interested entity, to order the preparation and publication of such an equality plan. It is wellestablished that the equality courts are not overburdened, and creating this additional role for the equality courts will unlikely lead to clogged court rolls. Empowering equality courts to oversee the development and implementation of equality plans would allow these courts to play a more significant role in combating systemic discrimination as well - which is one of the explicit aims of the Equality Act.

We also propose that Section 14 of the Equality Act in its current form should be amended to allow equality courts to take cognisance of the existence or non-existence of a respondent's equality plan, and whether the published equality plan is appropriate, in the determination of the fairness or unfairness of the alleged discrimination. Such an amendment would supplement the provision that already appears in Section 14 that equality courts must consider

'(i) whether and to what extent the respondent has taken such steps as being reasonable in the circumstances to - (i) address the disadvantage which arises from or is related to one or more of the prohibited grounds; or (ii) accommodate diversity'.

It would not be a stretch for equality courts to rule on the content of equality plans. They are already called upon to make value judgements in deciding on 'fair' or 'unfair' discrimination. In the context of disabled learners, in ruling on 'reasonable accommodation', the equality courts are already to some extent devising equality plans. In the case of Oortman v. St Thomas Aquinas Pri- vate School E Bernard Langton, ${ }^{77}$ e.g. the Mpumalanga equality court ruled that the respondent school had to readmit the learner and had to reasonably accommodate the learner. The court made specific orders to allow for access for the learner in her wheelchair to the classroom, washbasin and toilet. ${ }^{78}$

An audit of all laws calling on entities to draft equality/ equity plans should be considered and so should the coordination and harmonisation of similar duties created in related legislation, e.g. the Employment Equity $\mathrm{Act}^{79}$ which requires employers to submit employment equity plans that must indicate how affirmative action measures will be implemented ${ }^{80}$ and the Women Empowerment and Gender Equality Bill ${ }^{81}$ which requires designated bodies to submit annual compliance plans on gender education; women's health care and reproductive health; public education on prohibited practices, including gender violence and equal representation and participation in decision-making. ${ }^{82}$ The reporting obligations in these laws must be coordinated and harmonised so that all the relevant laws require one plan with the same content and same reporting cycle. Alternatively, those sections of other Acts calling for the preparation of equality/equity plans should be deleted, so as to create one overarching reporting duty.

The proposal set out in the Annexure requires all public and private bodies to prepare equality plans, irrespective of their size or influence. The preparation of an equality plan calls for consultation with affected communities and allows for reflection on how best to achieve substantive equality in a given context. Depending on the size and complexity of a particular public or private body, the preparation and content of an equality plan will vary significantly. A hairdresser's equality plan may amount to little more than a clearly visible sign posted at the entrance professing that all hair types are accommodated. On the other hand, as an example, a school's equality plan will have to address many interlocking and complex matters such as admission requirements, boarding placement policies, calculation of school fees, school culture, student governance structures, etc. To require small private entities to draft equality plans will therefore usually not be an onerous burden. To avoid the reporting obligations of larger bodies from becoming unduly onerous, one reporting obligation for all equality-related legislation should be created, as set out above. This would require an audit of all laws calling for equality/equity plans, and ensuring that these laws are harmonised.

An alternative approach would be to draft and prescribe codes of practice for particular sectors, e.g. education, service industry, sporting bodies, etc. to replace equali-

77. Equality Court Case 1/2010 (December 2010).

78. I. Grobbelaar-Du Plessis and C. Grobler, 'South Africa', 1 African Disability Rights Yearbook 307, at 320 (2013).

79. 55/1998.

80. Section 20 of the Employment Equity Act.

81. www.juta.co.za/media/filestore/2013/11/B50_2013.pdf (last visited 24 December 2017).

82. Section 4 of the Employment Equity Act. 
ty/equity plans. All entities operating in that particular sector would then be obliged to adhere to the relevant code of practice. These codes would have to be generic in nature, allowing each particular entity to interpret the applicable code in the context of its own operational and other requirements and circumstances. An opportunity to consult with the affected communities and stakeholders, and calling for the assistance of non-governmental organisations (NGOs) and civil society in drafting a tailor-made equality plan for that specific entity, would then also be absent. The proposal set out in the Annexure does not follow this approach, but rather opts for individualised equality plans.

A number of proposed amendments to other sections in the Act flow from this suggested approach (i.e. the preparation and publication of equality plans by all private and public entities, and empowering the equality courts to adjudicate on the content and implementation of equality plans), as set out in the Annexure.

In similar fashion, we propose to require state departments to also prepare, publish and implement equality plans, but that these plans not be submitted to the SAHRC. (The SAHRC would still have its normal monitoring and other duties as prescribed in its founding legislation.)

\section{Implications for South African Education Law}

Should the government accept this proposed model and amend the Equality Act and regulations accordingly and bring into effect the promotional part of the Equality Act, schools and faculties of education at universities, governing bodies, educators and learners will be impacted on significantly.

The departments of basic and higher education, all universities, including faculties of education and all schools would have to develop equality plans; inter alia on how they would, over time, eliminate systemic discrimination, individual instances of unfair discrimination, hate speech and harassment related to the prohibited grounds in its area(s) of operation; illustrate how it will advance substantive equality in its area(s) of operation and illustrate how it will foster good relations in its area(s) of operation between persons who share a prohibited grounds and persons who do not. A consultative process would have to be followed to develop these plans. These plans must be developed in a bona fide, inclusive manner allowing for input from all interested parties. These plans would then have to address matters such as curricula and assessment (the examples used and the questions asked); placement policies, codes of conduct, etc. - all in service of transforming schools into safe and inclusive spaces and producing learners and young adults attuned to the imperatives of living up to and celebrating diversity, substantive equality and dignity.
An example of the current approach to human rights education in South African high schools can be found in the grade 12 South African Life Orientation textbook, where a meagre total of 5 pages out of 244 are dedicated to human rights and discrimination by listing rights and examples of discrimination followed by two activities asking students to reciprocally, list rights and write down what violations would look like without any actual activity necessitating dialogue, reflection or action instructed to be undertaken for the exploration of these rights. ${ }^{83}$ For learners and citizens alike to develop a critical consciousness about human rights, it is important to remember that human rights are personal rights, they are not impersonal or relating to property and they affect the 'self'. For this reason, perspectives on critical consciousness which have a focus on self-awareness are useful to determine how we can achieve critical consciousness about human rights. Pitner and Sakamoto theorise that the first step to critical consciousness is a self-awareness of one's various social identities (gender, race, etc.) and the influence thereupon of factors like history, culture and politics. ${ }^{84}$ This is especially important in a South African social context if one considers our diverse society. They further theorise that we have a position and status within each of these identities which influences our perception of ourselves and others, e.g.: A male might have a privileged status in his position as a male from a gender identity perspective, but if his race in a specific context has been oppressed, he is simultaneously privileged and oppressed. ${ }^{85}$ Our social identity perspectives can give us different narratives about our realities. ${ }^{86}$ Pitner and Sakamoto refer to this as 'standpoint theory' and suggest that oppressed groups are often more aware of these narratives than nonoppressed groups. ${ }^{87}$ The complication with this selfawareness strategy is that, often, when the privileged become aware of their position and status within their privileged identity, this leads to them becoming defensive or feeling guilty instead of constructively considering how collaboration can happen between the privileged and oppressed towards human rights-relevant goals such as social justice. ${ }^{88}$ The way to counter this potential demotivation is by changing the perspective from being privileged to being an 'agent' whose privilege gives them access to social power while the oppressed can be seen as 'target groups' whose group memberships limit their access to power. ${ }^{89}$ This less threatening approach helps shift the thinking attitude on two important levels: ${ }^{90}$

83. Pearson Spot on Life Orientation Learner's Book (2017), 98-102.

84. I. Sakamoto and R. Pitner, 'Use of Critical Consciousness in AntiOppressive Social Work Practice: Disentangling Power Dynamics at Personal and Structural Levels', 35 British Journal of Social Work 435, at 442 (2005).

85. Ibid.

86. Ibid.

87. Ibid.

88. Ibid., at 444

89. Ibid.

90. Ibid. 
First, it helps agent group members to examine power differentials at a structural level and, thus, lowers their resistance to acknowledgement of their own privilege. Secondly, for target group members, this analysis identifies a common goal with the agent group (i.e. eradicating all forms of oppression at every level). It also makes the target group responsible in that they are able to see how their various social group identities may also place them in the agent group role (depending on the social context). Thus, target groups do not simply blame agent groups for owning social power; they join them in working toward social justice. Being able to critically examine how we are both targets and agents allows individuals to feel less threatened and more responsible for working toward social action.

If one considers that the beginning of developing critical consciousness also includes a critical self-consciousness, that helps frame the way human rights-related concepts can be taught to learners so that they do not simply consider some human rights relevant to them and others perhaps not because it does not directly relate to them, i.e. the learner who is 'privileged' enough to never have experienced problems with access to water and sanitation might not become critically conscious or internalise the values behind this human right because the learner feels it does not directly relate to his personal circumstances. Critical self-consciousness hence helps to start create a consciousness of our role in society as 'agents' who can assist with change and hence more open and invested to learning about those rights and how we can contribute towards achieving them to assist 'target groups' and collaborate in society. This realisation is the core of critical consciousness.

While this concept is useful, it is only the beginning of critical consciousness and the question still remains how we make this concept practical especially in a classroom. This is where dialogue comes in so that reflection can be achieved via conversation and subsequent action or praxis can eventually occur.

Most models of critical consciousness teaching note that critical consciousness, specifically dialogue and reflection, can be made practical via activities such as journaling (self-reflection on issues and experiences), but, more importantly, via class discussions ${ }^{91}$ which can even take the form of structured debate for which guidelines are have been created by Pitner and Sakamoto ${ }^{92}$, if relevant. Rugut and Osman note Freire's perspective on dialogue and that 'dialogic action challenges mediating social realities by posing them as problems that can be analysed critically by those who have direct experience of them'. ${ }^{93}$ They hence propose the use of the Freirean

91. K.A. McDonough, Performing Critical Consciousness in Teaching: Entanglements of Knowing, Feeling and Relating. PhD Thesis, University of Massachusetts (2015), 82.

92. I. Sakamoto and R. Pitner, 'Cultural Competence and Critical Consciousness in Social Work Pedagogy', Encyclopedia of Social Work August 6 (2016).

93. E.J. Rugut and A.A. Osman, 'Reflection on Paulo Freire and Classroom Relevance', 2 American International Journal of Social Science 23, at 26 (2013). model of 'problem-posing education' to counteract the banking model of education: ${ }^{94}$

In this model, the teacher and learner discuss and analyze their experiences, feelings and knowledge of the world together. Instead of the belief that learners' and teacher's situation in the world is fixed, as the banking model suggests, the problem-posing model explores problems or realities people find themselves in as something which can be transformed.

Rugut and Osman then suggest that the problem-posing model can be used to make learners aware of their social identities, of privilege or oppression, by making use of dialogue in the form of 'the culture circle' where learners and teachers engage in non-hierarchal conversation around learners' current social realities and identifying generative themes related to their social realities: ${ }^{95}$

These themes, which are related to nature, culture, work, and relationships, are discovered through the cooperative research of educators and students. They express, in an open rather than propagandistic fashion, the principle contradictions that confront the students in their world ... This involves creating a democratic space where every one's voice has equal weight. The conditions needed for this have to be actively created as it does not often occur naturally. This can mean challenging cultural, gender and other status related power relationships and stratifications.

Once these themes come to light and learners are exposed to each other's realities, a process of codification and decodification takes place where learners can form a picture of a reality they might not have previously related to or considered themselves involved in:

Codification is a way of gathering information in order to build up a picture (codify) around real situations and real people. Decodification is a process whereby the people in a group begin to identify with aspects of the situation until they feel themselves to be in the situation and be able to reflect critically upon its various aspects, thus gathering understanding.

It is this awareness created by dialogue which cultivates a critical consciousness of learners' social realities and where education is used not to adapt them to their current reality but to understand and transform their reality because real problems and needs are discovered. ${ }^{96}$ From this shared understanding, learners can start to interrogate their own social identity and potential power in these realities.

\section{Conclusion}

In this article, we argued for amendments to the Equality Act to craft an explicit duty to transform South Afri-

94. Ibid., at 24

95. Ibid., at 25

96. Ibid., at 27 
cans' hearts and minds - a duty that rests on all persons in all contexts. The specific context of this article relates to education and a proposed duty to be placed on all schools to take a much more proactive and intrusive approach to transforming its learners. There is support to be found for this proposal in South African and international law. We briefly conclude by summarising the most pertinent South African and international law principles.

MEC for Education: Kmazulu-Natal v. Pillay ${ }^{97}$ involved a school who refused permission to a learner to wear a nose stud to school. The evidence showed that in terms of the learner's culture, wearing this nose stud was seen as celebrating the coming womanhood of the learner. The Constitutional Court held that the school's code of conduct unfairly discriminated against the learner for not allowing for exemptions to the code for inter alia bona fide cultural reasons. The case did not directly deal with learners' hearts and minds, but some of the paragraphs in the judgement may be read as endorsing the approach set out in this article - an approach that would enforce difficult conversations in classrooms, where learners' diverse backgrounds and cultures and viewpoints are celebrated in such a way that the core values of the Constitution are strengthened; ${ }^{98}$ in service of changing learners' hearts and minds.

International law also speaks directly to a duty on (South African) schools to promote equality in a much more thorough-going manner than is currently the case in classrooms. In terms of Section 39(1)(b) of the Constitution, when interpreting the Bill of Rights, all South African courts must consider international law. The rights to substantive equality and education are explicit-

97. 2008 (1) SA 474 (CC).

98. For example, see para. 104: 'Teaching the constitutional values of equality and diversity forms an important part of education. This approach not only teaches and promotes the rights and values enshrined in the Constitution, it also treats the learners as sensitive and autonomous people who can understand the impact the ban has on [the learner who was refused permission to wear a nose stud]'; para. 172: 'A school is an ideal place to educate other learners about the difference between fashion and cultural practices and should an exemption for nose-studs be granted, a school would be obliged to furnish such education to its learners'; para. 173: 'Schools are excellent institutions for creating the dialogue about culture that will best foster cultural rights in the overall framework of our Constitution. Schools that have diverse learner populations need to create spaces within the curriculum for diversity to be discussed and understood, but also they need to build processes to deal with disputes regarding cultural and religious rights that arise'; para. 185: 'It is inevitable given the extraordinary transformation that the school in this case has undergone that conflict about the school and its rules should arise from time to time. It needs to be emphasised however, that the strength of our schools will be enhanced only if parents, learners and teachers accept that we all own our public schools and that we should all take responsibility for their continued growth and success. Where possible processes should be available in schools for the resolution of disputes, and all engaged in such conflict should do so with civility and courtesy. By and large school rules should be observed until an exemption has been granted. In this way, schools will model for learners the way in which disputes in our broader society should be resolved, and they will play an important role in realising the vision of the Preamble of our Constitution: a country that is united in its diversity in which all citizens are recognised as being worthy of equal respect' ly guaranteed in the South African Bill of Rights; therefore, relevant international law principles are directly on point in how these rights (substantive equality read with the right to education) should be concretised.

The Abidjan Principles on the human rights obligations of states to provide public education and to regulate private involvement in education concretise in some detail what international human rights law on education implies for South African education law. ${ }^{99}$ These principles were adopted in February 2019 in Côte d'Ivoire after a process of consultation and drafting that lasted three years. ${ }^{100}$ The consultations involved legal practitioners, specialists in education and relevant community members from diverse localities. ${ }^{101}$ One of the aims of the drafters of these principles was to explain what international human rights law implies for states in providing education. ${ }^{102}$ Over the years, many bodies of the United Nations and other human rights institutions had been publishing a variety of documents on the topic, and there was a need to bring all of these together in a single document to confirm the ruling legal principles. ${ }^{103}$

Many of the Abidjan Principles speak directly to equality and discrimination and imply a duty on schools to ensure their learners inculcate appropriate values relating to inclusion and diversity. The first principle provides that 'States must respect, protect, and fulfil the right to education of everyone within their jurisdiction in accordance with the rights to equality and non-discrimination'. This principle is then spelt out in much detail in the explanatory document accompanying the principles. Speaking directly to the transformation of hearts and minds, the explanatory notes refer to four dimensions (our emphasis):

a fair redistributive dimension to address socioeconomic disadvantages;

a recognition dimension to combat stigma, stereotyping, prejudice, and violence, and to recognise the dignity of human beings and the intersectionality of different grounds of discrimination;

a participative dimension to reaffirm the social nature of people as members of social groups and the full recognition of humanity through inclusion in society; and

a transformative dimension to accommodate difference as a matter of human dignity and institute systemic change.

The principles espoused in South African and international law require a pro-inclusion and pro-diversity

99. www.abidjanprinciples.org/en/principles/overview (last visited 23 June 2020).

100. www.abidjanprinciples.org/ (last visited 10 July 2020).

101. www.abidjanprinciples.org/en/background/overview (last visited 10 July 2020).

102. www.abidjanprinciples.org/ (last visited 10 July 2020).

103. www.abidjanprinciples.org/en/background/overview (last visited 10 July 2020). 
approach as, e.g. set out in the bulleted proposals at the end of the fifth section of this article. In our view such a pro-inclusion and pro-diversity approach may be facilitated by the amendments proposed to the Equality Act in this article.

Annexure: Proposed Amendments to the Equality Act and Accompanying Regulations

The proposed amendments to the Equality Act and accompanying regulations follow below. Additions are indicated by underlining and deletions by strikethrough.

Sec. 25(4)(b): “All Ministers must within their available resources prepare, publish and implement equality plans, in the prescribed manner, which must include a time frame for implementation, and which must be formulated in consultation with the Minister of Finance".

Sec 25(5) (a) The equality plans must, within two years after the commencement of this Act, be submitted to the South African Human Rights Commission to be dealt with in the preseribed manner.

(b) The South Afriean Human Rights Commission must consult with the Commission on Gender Equality when dealing with the plans contemplated in paragraph (a).

Section 27:104

The Minister must develop regulations in relation to this Act and other Ministers may develop regulations in relation to other Acts which require any person directly or indirectly contracting with the State or exercising public power, non-governmental organisations, community-based organisations, traditional institutions, companies, closed corporations, partnerships, clubs, sports organisations, corporate entities and associations, where appropriate, in a manner proportional to their size, resources and influence, to prepare and publish equality plans or abide by prescribed codes of practice or report to a body or institution on measures to advancepromote equality.

Section 14(3): ${ }^{105}$

(j) Whether the respondent has developed an equality plan or not;

(k) If the respondent has developed an equality plan whether this plan sets out how systemic unfair discrimination, individual instances of unfair discrimination, hate speech and harassment will be eliminated over time; whether this plan sets out how good relations will be fostered between persons who share a prohibited ground and persons who do not share it; whether the plan's goals and objectives are directed towards the

104. We propose that Section 26 and 27(1) be deleted and incorporated into an amended Section $27(2)$

105. These additions will allow an equality court to consider the relevance and content of a respondent's equality plan (or inadequate plan or absence of an equality plan) in determining if the alleged discrimination was fair or unfair. advancement of equality; whether the measures to be implemented will achieve the stated goals and objectives; whether the measures adopted to monitor the implementation of the equality plan are appropriate; whether the criteria to evaluate the implementation of the equality plan are appropriate; whether the equality plan will achieve reasonable progress towards the eradication of systemic discrimination and the advancement of equality; whether time frames have been set and/or met and if not whether cogent reasons have been provided for this omission and whether measures have been put in place to expedite the implementation of the equality plan.

Sec 20(2) Proceedings under section 21(1)(e), (f) and (g) may be instituted by any of the persons or associations listed in section 20(1) as well as the South African Human Rights Commission, the Commission for Gender Equality or the Director-General of the relevant State department.

Sec. 21:

(1) The equality court before which proceedings are instituted in terms of or under this Act must hold an inquiry in the prescribed manner and determine whether one or more of the following has taken place, as alleged:

a. unfair discrimination

b. hate speech

c. harassment

d. the publication of material that illustrates the intention to unfairly discriminate

e. the omission to prepare an equality plan as required in terms of this Act and any regulations promulgated in terms of this Act

f. the omission to publish an equality plan as required in terms of this Act and any regulations promulgated in terms of this Act

g. the omission to adequately implement an equality plan

Sec. 21(2)

(b) a declaratory order, including a declaratory order whether sufficient progress has been made with the implementation of the respondent's equality plan and/or the measures to expedite the implementation of the respondent's equality plan

(q) an order to prepare an equality plan in terms regarded appropriate by the court and as required in terms of this Act and any regulations promulgated in terms of this Act

(r) an order to publish an equality plan in terms regarded appropriate by the court and as required in terms of this Act and any regulations promulgated in terms of this Act

(s) an order to take appropriate measures to expedite the implementation of the respondent's equality plan 
The following regulations are proposed, for further refinement, to flesh out the content of progress reports (section 25(3)(c)) and equality plans (section 25(4)(b) and section 27).

Request for progress report (sec. 25(3)(c) of the Act)

1.

1. A request from a constitutional institution for a progress report regarding the number of cases and the nature and outcome thereof contemplated in section 25(3)(c) of the Act, must correspond substantially with Annexure (XX) ${ }^{106}$ and must-

a. be in writing;

b. be addressed to the Director-General of the Department;

c. be signed by the chief executive officer of the constitutional institution, or a person designated by him or her;

d. indicate the period for which the information is required;

e. indicate the date on which the report is due;

f. indicate which of the following particulars are required -

i. in regard to the number of cases -

(aa) the number of cases instituted in the equality court in terms of section 20(2) of the Act; and

(bb) the number of cases finalised by the equality court or an alternative forum;

ii. in regard to the nature of the cases -

(aa) the ground of discrimination;

(bb) the category of discrimination involved for example in respect of procurement, employment, access to places and facilities, accommodation (land/housing), education, sport, insurance, provisioning of goods and services, registered clubs, advertisements etc.;

(cc) the area from which the complaint originates (rural/metropolitan);

(dd) the age, gender, race, and where applicable, the disability of the complainant;

(ee) the gender and race of the person against whom the allegations are made;

iii. in regard to the outcome of the case -

(aa) the finding and order of the equality court; or

(bb) in the event of the case being dealt with by an alternative forum, the name of the forum, the outcome of the case and form of dispute resolution mechanism used to solve the case;

g. invite the Director-General of the Department to make any additional relevant comments, either in general or in respect of a specific case, or in respect of any apparent tendencies in respect of the cases reported.

Preparation of equality plan by State (sec. 25(4)(b))

2.

1. An equality plan contemplated in section 25(4)(b) of the Act must be prepared-

a. within two years after the commencement of this regulation;

b. with due consideration to the provisions of section 28(3) of the Act;

c. for a period of five years coinciding with the financial year contemplated in the Public Finance Management Act, 1999 (Act No. 1 of 1999); and

d. subsequently at intervals of not exceeding five years beginning with the date of last publication.

2. In preparing an equality plan contemplated in this regulation, a Minister must consult -

a. the Minister of Finance;

b. the Commission on Gender Equality, the Human Rights Commission, the Commission for the Promotion and Protection of the Rights of Cultural, Religious and Linguistic Communities and the Public Protector; and

c. affected communities and affected business sectors through any appropriate means including public hearings.

3. An equality plan contemplated in this regulation must-

a. be in writing;

b. be signed by the responsible Minister;

c. illustrate how it will over time eliminate systemic discrimination, individual instances of unfair discrimination, hate speech and harassment related to the prohibited grounds in its area(s) of operation;

d. illustrate how it will advance substantive equality in its area(s) of operation;

e. illustrate how it will foster good relations in its area(s) of operation between persons who share a prohibited grounds and persons who do not;

f. contain specific and measurable objective(s), timeframes for the implementation of each objective, the mechanisms to monitor the implementation of each objective and the criteria to evaluate the implementation of the equality plan.

g. within 30 days after the responsible Minister has signed it be -

i. published in the Gazette;

ii. made available on the website, if any, of the relevant department;

iii. circulated under the signature of the relevant head of the department to all its employees;

iv. tabled in Parliament; and

v. submitted to the Minister of Finance. 


\section{Availability of Act in official languages}

3.

1. The Minister must, for purposes of section 31(2)(b) of the Act, make the Act available in plain language ${ }^{107}$ in all official languages by -

a. publishing it in the Gazette;

b. putting it on the website of the Department;

c. submitting it to all the constitutional institutions; and

d. circulating it to all magistrates' offices.

2. The constitutional institutions and magistrates' offices must, during office hours, make the Act available to every person who wishes to inspect the Act in plain language and in the official language so requested.

Preparation of equality plan by entities other than the State (new proposed sec. 27) ${ }^{108}$

4.

1. This regulation applies to all persons directly or indirectly contracting with the State or exercising public power, non-governmental organisations, community-based organisations, traditional institutions, companies, closed corporations, partnerships, clubs, sports organisations, corporate entities and associations.

2. All entities bound by this regulation must within two years after the commencement of this regulation prepare an equality plan as contemplated in section 27 of the Act.

3. An equality plan referred to in subregulation (2) must -

a. illustrate how it will over time eliminate systemic unfair discrimination, individual instances of unfair discrimination, hate speech and harassment related to the prohibited grounds in its area(s) of operation;

b. illustrate how it will advance substantive equality in its area(s) of operation;

c. illustrate how it will foster good relations in its area(s) of operation between persons who share a prohibited ground and persons who do not;

d. be prepared for a period of five years and must coincide with the financial years of the entity;

e. subsequently be prepared at intervals of not exceeding five years beginning with the date of last publication;

f. be prepared after consultation with affected communities and affected business sectors through any appropriate means;

g. be in writing;

h. be signed by the chief executive officer of the entity; i. contain specific and measurable objective(s), timeframes for the implementation of each objective, the mechanisms to monitor the implementation of each objective and the criteria to evaluate the implementation of the equality plan;

j. within 30 days after the signing thereof be circulated under the signature of the chief executive officer of the entity to all its employees and made available for inspection at each of its offices and on its website, if any.

Including human rights and equality law in the school curriculum

5. Over and above any other duty created in terms of these regulations, the Department of Basic Education must within two years after these regulations have entered into force, develop an action plan on how principles of substantive equality and equality law will be embedded in the curriculum from the first to last school year of all public and private schools. ${ }^{109}$
107. In this article, we treat as self-evident the benefits of a plain language approach. A full argument on why the Equality Act should be drafted in plain language is beyond the scope of this article.

108. The regulations should also prescribe a clear process to be followed in developing equality plans to ensure that inclusive, participatory processes are followed to allow for substantive input from internal and external stakeholders, civil society and NGOs.
109. See, e.g.www.reaseheath.ac.uk/wp-content/uploads/2012/05/ Equality-Curriculum-Handbook.pdf for possible approaches to this proposal (last visited 24 December 2017). 